\title{
() Los trazos de la disgregación: ¿ el juicio político al Gobernador ¿ Martínez Baca (M endoza, 1973-1974)
}

María Virginia Mellado ${ }^{1}$

\section{Los peronismos en pugna: la experiencia política de $\mathbf{1 9 7 3}$}

Este artículo analiza la modalidad que exhibieron las divisiones Einternas del peronismo en la provincia de Mendoza, fenómeno que corroyó la experiencia gubernamental abierta en 1973. En particular, el trabajo explora las tensiones y la fragmentación que manifestó el peronismo en el gobierno provincial y su particular forma de resolución de los conflictos internos a través de la realización del juicio político al gobernador Alberto Martínez Baca, quien se desempeñó en esas funciones desde mayo de 1973 hasta junio de 1974.

La puja entre los distintos sectores y grupos que integraron el "movimiento peronista" en los años 70 se presentó de distintas formas en los gobiernos provinciales. En el caso de Buenos Aires, el gobernador Oscar Bidegain fue destituido como consecuencia del ataque del Ejército Revolucionario del Pueblo (ERP) al Regimiento $X$ Húsares de Pueyrredón del Ejército (Gillespie 1987:194). En el caso cordobés, Ricardo O bregón Cano fue retirado de sus funciones por medio de un "golpe policíaco" (Gillespie 1987:168) y luego intervenida la provincia por orden del Poder Ejecutivo N acional. El caso de M endoza es distinto: las tensiones entre los grupos contendientes se dirimieron a través de la salida que presentaba el juicio político, mecanismo instaurado en la constitución provincial. Si bien esta resolución no fue definitiva ya que no logró saldar la crisis del partido y del gobierno, se convirtió en

1 Laboratoire de DémographieHistorique(LDH). Ecoledes Hautes Etudes en Sciences Sociales (EHESS)/UNCuyo. Esteartícul o constituye un avance de una investigación más extensa sobre la morfología de las élites provinciales a partir de 1970, e-mai l: vmellado@lab.cricytedu.ar. 
el instrumento que utilizaron las fracciones del partido para alejar al gobernador de su puesto, habilitando la intervención federal.

Los estudios que se interrogan acerca de la singular fisonomía que adquieren los problemas de la vida política en los distintos contextos provinciales han proliferado en los últimos años. Acerca del fenómeno peronista se cuenta con estudios que han explorado sus orígenes atendiendo a los distintos tipos de estructura social, actores y formaciones políticas que presentan las provincias argentinas (Tcach 1991; Macor e Iglesias 1997; Macor y Tcach 2003). No obstante, son menos frecuentes las investigaciones que avanzan en la caracterización del peronismo en los años de 1970, atendiendo a la especificidad de las tramas políticas provinciales. Generalmente las investigaciones que toman como objeto este periodo han colocado el énfasis en la indagación de las organizaciones armadas (Gillespie 1987; Pozzi y Schneider 2000; Altamirano 2001; Lanusse 2005) y la protesta social (Gordillo 1991; Brennan 1996; Tortti 1998). El gobierno de Martínez Baca ha sido poco investigado. A excepción de algunos estudios de divulgación masiva (Cueto et al. 1996; M icale 2004), la temática propuesta no ha recibido el aporte de especialistas. Por ello, esta investigación ha requerido la reconstrucción de los principales fenómenos de la gobernación como así también la problematización de los sucesos en relación con la literatura del período.

Esta investigación se ha nutrido especialmente de los debates parlamentarios reproducidos en los Diarios de Sesiones y diarios y revistas políticas de la época donde se reprodujeron testimonios y entrevistas a los dirigentes partidarios y a los implicados del juicio político. Asimismo se ha recurrido a testimonios orales de miembros de las organizaciones armadas, políticos y sindicalistas para explorar el universo de significaciones de los actores sobre el fenómeno peronista, como así también el recuerdo que suscitó la lucha facciosa entre las distintas tendencias que atravesaron el movimiento político en la etapa setentista.

Para alcanzar los objetivos prefijados, el artículo analiza el contexto político de Mendoza a partir del llamado a elecciones, la selección de candidaturas y los resultados de los comicios. Asimismo hace hincapié en rescatar la conformación de los cuadros políticos y administrativos de la gobernación de Martínez Baca y los principales conflictos que desarrolló el partido una vez en el gobierno. Finalmente se indaga sobre las causales del juicio político, las estrategias Ilevadas adelante tanto 
por la acusación como por la defensa y la solución final diseñada por la $\mathrm{N}$ ación para resolver la puja intestina entre las distintas tendencias.

\section{La política mendocina en los años 70: el escenario electoral y la administración de Martínez Baca}

\subsection{La competencia electoral de 1973: candidaturas, partidos y fracciones}

La apertura democrática en 1973 se desencadenó como consecuencia del fracaso del proyecto de la denominada "Revolución Argentina". Las fuerzas armadas decidieron conducir el país detentando un discurso "prescindente de la política" (De Riz 2000:183), orientado a la lógica de la eficiencia y de la política-gestión. Por lo tanto, suprimieron los partidos y con ello los canales de expresión popular. La represión y la censura fueron los mecanismos utilizados para contener el conflicto social. Por su intermedio, se eliminó la pluralidad de ejes de conflicto (Waldmann 1982:223), polarizando el enfrentamiento político entre militares y el arco popular integrado por actores heterogéneos. O bstruidos los canales tradicionales de expresión, proliferó un clima de convulsión y radicalización política.

En ese clima, Mendoza, al igual que otros centros urbanos del país como Córdoba y Rosario, experimentó fenómenos de protesta social y movilización política con altos grados de violencia. El denominado "Mendozazo" en abril de 1972, protesta social de algunas características similares a las exhibidas en los sucesos de Córdoba en mayo de 1969, conllevó a la dimisión del gobernador Gabrielli y el recambio de las autoridades provinciales. Esa manifestación de masas donde se desbordaron los canales de representación de los intereses sociales, mostraba una enconada oposición al gobierno militar por las medidas antipopulares² tomadas en los primeros meses de 1972. La protesta puntual circunscripta al aumento tarifario de la luz aglutinó a las fuerzas opositoras manifestando el peso que poseían para la deter-

2 La empresa estatal Aguay Energía había establ ecido un importanteaumento del as tarifas eléctricas que alcanzaban hasta un $300 \%$, lo que suscitó la protesta de amplios sectores sociales, especial mente aquellos que contaban con menores recursos. Los Andes, 3/4/72:6; 4/4/72:4 y 5; 5/4/72:1, 5-10; 6/4/72:4. Mendoza, 3/4/72:8; 4/4/72:4; 5/4/72:1, 2, 5, 6-15. Cfr. (Cueto et al. 1996:29). 
minación de políticas gubernamentales. Entre los sectores movilizados se encontraban los maestros adheridos al SUTE ${ }^{3}$ bajo el liderazgo de Marcos Garcetti, quienes reclamaban al gobierno provincial por mejoras salariales. En este sentido, la composición social de quienes se movilizaron en el "M endozazo", reviste algunas diferencias significativas con la presentada en Córdoba en 1969. La particular composición de la estructura económico-social cordobesa, donde la industria automotriz era el polo más dinámico de la economía regional (Brennan 1996), llevó a que la representación obrera fuera mayor que la presentada por el caso mendocino. Asimismo, el peso y la densidad de la institución universitaria fue mayor que en Mendoza.

De esta manera, la participación de masas, ocluida por el gobierno del presidente Lanusse, fue el escenario propicio para engrosar las filas del peronismo. Perón se erigía como la figura que podía apaciguar los ánimos exacerbadosy devolver la gobernabilidad a un país anómico. Las fuerzas sociales se habían convertido en poder de veto ante el gobierno de la "Revolución Argentina". A partir de las tratativas en el seno del Gran Acuerdo Nacional, Lanusse buscaba incorporar nuevamente al peronismo a la vida política del país para frenar a los grupos radicalizados encauzando el conflicto político por canales institucionales. Si bien el presidente quería conservar una cuota de poder para las FFAA, el desgaste sufrido por el gobierno y el escenario de conflicto impidieron esa posibilidad. Levantada la proscripción del peronismo, el partido se preparaba para las elecciones planificadas para marzo de 1973.

El Ilamado a elecciones generales aceleró el proceso de organización interna de los partidos políticos. En Mendoza, los tres partidos mayoritarios - el peronista, el radical y el partido demócrata- se encontraban con posibilidades reales de ganar las elecciones. Dentro del proceso de reconstrucción partidaria planteado por el calendario electoral, el partido demócrata rápidamente logró flanquear sus diferencias internas ${ }^{4}$ y establecer líneas concretas en la campaña a través de un acuerdo interno entre grupos que permitiría llevar adelante candidaturas consensuadas por un amplio espectro del partido. En este

3 Sindicato Único deTrabajadores de la Educación.

4 Claves para interpretar los hechos, 12/1/73:5. Esta publicación periódica, de aparición quincenal, era dirigida por Fabián Calle y su J efe de redacción era Carlos Quirós. En sus pági nas se debatía la real idad política provincial y nacional. Claves para interpretar los hechos dejó de editarse con esa frecuencia en el año 1974, ya que conflictos políticos, tales como la explosión de una bomba en su redacción, impidieron su distribución regular. 
escenario, Eduardo Vicchi fue proclamado candidato a gobernador y Amadeo Frúgoli candidato a senador nacional ${ }^{5}$. Se trató de los máximos representantes de las fuerzas que polarizaban el partido.

En cambio, los radicales solucionaron sus diferencias a través de elecciones internas. El escenario provincial mostró algunas divergencias con el panorama nacional, ya que el sector balbinista era ampliamente mayoritario. La fórmula Alfredo Mosso-Erminia Ramos de Vázquez se impuso en las contiendas partidarias ante la oposición alfonsinista, liderada en la provincia por el Dr. Santiago Felipe Llaver, diputado nacional durante el gobierno de Illia.

El escenario pre electoral del peronismo se mostró más complejo respecto de sus adversarios. Si bien se logró una fórmula de consenso que contemplara los sectores con mayor poder, la selección de los candidatos no estuvo ajena a conflictos. Había cinco posibles candidatos disputando el cargo de gobernador: Ernesto Corvalán $\mathrm{N}$ anclares, candidato a gobernador del justicialismo en 1966, Carlos Evans, go bernador de Mendoza entre 1952 y 1955, Pedro Cámpora, hermano de Héctor, Horacio Farmache, militar retirado y Alberto Martínez Baca. La primera alternativa que surgió fue llevar adelante la candidatura de $\mathrm{H}$ oracio Farmache, dirigente que contaba con una destacada trayectoria política dentro del partido. Su alejamiento del cargo estuvo dado por la "compleja"6 relación con Cámpora, el elegido de Perón para las elecciones presidenciales de marzo de 1973. Evans entendió que era difícil competir con el hermano del candidato a presidente, por lo que se conformó con integrar en primer término la lista de candidatos a senadores nacionales. Según el testimonio de Alfredo Guevara, "Pedro Cámpora, el hermano de Héctor J., él era el candidato, el candidato real, porque era el delegado de Perón en Mendoza (...) él era el delegado, el tipo que tenía más apoyo en ese momento de la estructura política, y además era hermano de H éctor (...) era el candidato que iba seguro al cargo. Lo de Martínez Baca lo decidió Héctor. Y si querés te digo los motivos por los cuales no eligió a su hermano. (...) Héctor se lo dijo a Pedro directamente ' $y$, disculpame, porque yo soy candidato a presidente vos no podés ser candidato a gobernador'"7.

5 Claves para interpretar los hechos, 12/1/73:6.

6 Claves para interpretar los hechos, 22/12/72:43.

7 Entrevista realizadaal dirigenteAlfredo Guevara en el año 2003 (DeMarinis y Ábalo 2005:51). 
Finalmente la candidatura para gobernador cayó sobre Alberto Martínez Baca. Frente al problema ético que revestía la candidatura de Pedro Cámpora, Martínez Baca contaba con el apoyo de Isabel Perón, vínculo que provenía de 1966. La mujer de Perón conocía de cerca a Martínez Baca ya que en las elecciones de abril de 1966 éste fue candidato a vicegobernador acompañando en la fórmula a Ernesto Corvalán Nanclares.

M artínez Baca pertenecía a la rama política. Nacido en la provincia de Buenos Aires, obtuvo el título de farmacéutico y residió luego en General Alvear y San Rafael donde empezó su carrera política. El candidato a gobernador se desempeñó previamente como concejal, legislador provincial y candidato a vicegobernador (Cueto et al. 1996:23). Su trayectoria dentro del partido le permitió distanciarse del neoperonismo, encabezado en la provincia por Serú García ${ }^{8}$. M artínez Baca se presentaba como el candidato de la Juventud; no obstante, las tensiones entre el líder y el sector juvenil estaban presentes. Martínez Baca no contaba con una base de apoyo propia que le permitiera enfrentar al sector sindical. Por ello, encontró en este sector el sostén para su candidatura.

El acercamiento con la «Tendencia Revolucionaria» se circunscribe a un acuerdo coyuntural. En referencia al apoyo recibido por Martínez Baca, el testimonio de un dirigente de Montoneros, Alfredo Guevara, es clarificador en cuanto argumenta que si bien había acercamientos entre el sector de la juventud y el candidato a gobernador, éste no pertenecía a sus filas; a su juicio, su trayectoria política más bien se adecua a la de un peronista histórico. Martínez Baca "no fue alguien puesto por Montoneros, sólo porque era simpático con ellos. Era el presidente del partido en San Rafael. Había velado a Balbuena, un militante de las FAP, en el partido y había muchas cosas por las cuales nosotros lo considerábamos como cercano a la Tendencia (...)

8 El caso de las elecciones gubernamentales en Mendoza el 7 de abril de 1966 fue emblemá tico ya que el Partido J usticialista concurrió dividido a los comicios. En esta oportunidad se produjo el enfrentamiento entre el neoperonismo, apoyado por el sector vandorista y el justicialismo. El neoperonismo bajo la denominación de "Movimiento popular mendocino" había proclamado la fórmulaA l berto Serú García-Ventura González. No obstante, el apoyo de Perón recayó en la fórmula hegemonizada por Emesto Corvalán Nanclares y A lberto Martínez Baca a través de la gestión de su esposa I sabel. Los resultados electorales arrojaron la victoria del Partido Demócrata con la fórmula Emilio J ofré-Carlos Gal letti. La importancia de la elección se tradujo en la victoria de Corvalán Nanclares, el candidato bendecido por Perón por sobre el Serú García, apoyado por las filas vandoristas. El proyecto vandorista de incorporación al proceso electoral quedó trunco. Cfr: James 1999:243; DeRiz 2000:28. 
cercano, pero no de ella (...) Martínez Baca no era montonero, no respondía a las líneas montoneras" ${ }^{\prime \prime}$.

Por directivas del partido, el cargo para vicegobernador debía ser asignado a un gremialista. A través de reiteradas negociaciones, las 62 organizaciones provinciales decidieron integrar las listas de candidatos con sus funcionarios, consumando la fórmula Alberto $M$ artínez Baca-Carlos Mendoza. Mendoza era obrero metalúrgico y secretario General de Unión O brera M etalúrgica (U O M ) de M endoza a partir de 1957. Su trayectoria gremial lo ubicaba en los años de la "resistencia peronista", sufriendo la represión de los años "duros" de la "revolución libertadora". A través del plan CONINTES (Conmoción Interna del Estado), el dirigente gremial fue detenido en 1960, recuperando su libertad durante el gobierno de Illia. En esos años retomó la actividad sindical, siendo designado secretario general de las 62 organizaciones hasta el año 66, donde pasó a ser secretario adjunto de la Confederación General del Trabajo (CGT) de Mendoza. Durante el gobierno de Illia se desempeñó como senador provincial (Cueto et al. 1996:5) y a partir de 1967, fue secretario de Previsión de la Unión Obrera Metalúrgica ${ }^{10}$. Mendoza recuerda que su peso político derivaba del apoyo que le ofrecía la U O M por su militancia: "me propuso la U O M, se hizo un congreso acá, en realidad dos congresos, se cambiaba el candidato a gobernador pero me dejaban a mí. 0 sea, con los antecedentes que yo tenía del Plan CON INTES, de estar preso, acusado de poner bombas y todas las historias esas"11.

Las elecciones del 11 de marzo de 1973 mostraron resultados claros tanto a nivel nacional como provincial. El justicialismo obtuvo una abultada victoria en la contienda electoral frente a demócratas y radicales. La fórmula encabezada por Alberto Martínez Baca obtuvo 245.010 votos frente a 111.153 del partido demócrata. En la elección provincial, el Frente Justicialista de Liberación (FREJU LI) ${ }^{12}$ no alcanzó a reunir el caudal de votos necesarios para evitar el ballotage ${ }^{13}$. No

9 Entrevista realizadaal dirigenteA Ifredo Guevara en el año 2003 (DeMarinis y Á balo 2005:52-53).

10 Claves para interpretar los hechos, 26/1/73:5-6.

11 Entrevista a CarlosA. Mendoza, vicegobernador de Mendoza (1973-1974) realizada en el año 2003 (De Marinis y Ábalo 2005:206).

12 El Frente J usticialista de Liberación estaba integrado por el Partido J usticialista (PJ ), el Movimiento de Integración y Desarrol lo (MID), el Partido Popular Cristiano (PPC), y el Partido Conservador Popular (PCP).

13 Los Andes, 13/3/73:1. 
obstante, el 15 de abril, este partido se quedó con la victoria definitiva a través de un apoyo masivo en las urnas, obteniendo el $71,46 \%$ de los sufragios ${ }^{14}$. Los votos del radicalismo confluyeron en el apoyo al peronismo durante el ballotage. De esta manera, el éxito electoral del FREJU LI se traducía en un apoyo popular importante y mayoría en las dos cámaras legislativas. Sólo el Partido Demócrata, asociado con un sector de la Iglesia católica, se mostró opositor al nuevo gobierno ${ }^{15}$.

\subsection{El inicio de la gobernación peronista: crisis y conflicto al interior del partido gobernante}

G anadas las elecciones, las tensiones internas comenzaron a vislumbrarse. Los sectores políticos perdieron el relativo equilibrio que habían logrado durante la campaña. La fórmula que había resultado ganadora encerraba el enfrentamiento entre sectores del peronismo y el diseño de proyectos ideológicos disímiles. Mientras que los viejos sectores peronistas buscaban reeditar un gobierno como el encarnado por Perón entre 1946-1955, los sectores juveniles entendían la toma del poder como un momento para la constitución del «socialismo nacional».

Las visiones contrapuestas adquirieron una fisonomía clara a partir del reparto "equitativo" de puestos en los ministerios. El ministerio de $\mathrm{H}$ acienda recayó sobre un viejo técnico del partido, Benedicto Caplán, quien tuvo una activa participación en la compra de la Bodega Giol por parte del Estado en 1954. El ministerio de O bras y Servicios Públicos también recayó en un viejo cuadro del peronismo, Roberto Carretero, quien se había desempeñado como rector de la Universidad Nacional de Cuyo hasta su intervención en 1955'16. Sebastián Baztán fue designado como ministro de economía.

\footnotetext{
14 Los resultados parciales arrojaron 366.877 parae FREJULI y 138.892 para el P. Demócrata. Los Andes, 16/4/73:1. El escrutinio definitivo confirmó que el $71,26 \%$ de los votos habían quedado para la fómmula Martínez Baca-Mendoza. Los Andes, 19/4/73:6. Cfr. (Cueto et al. 1996:36).

15 La Iglesia Católica, a través de su autoridad máxima en la Provincia, Monseñor Maresma, había sugerido que el laicado católico sufragara en contra del FREJULI. Cf. Los Andes, 4/3/73:11. No obstante, la institución católica no respondía en su totalidad a esta visión; ya que se percibía cierta heterogeneidad dentro de sus filas. Un importante sector vinculado con el movimiento de Sacerdotes del Tercer Mundo eran cercanos ideológica y políticamente al peronismo revolucionario.

16 Claves para interpretar los hechos, 8/6/73:4. Los Andes, 25/5/73:11.
} 
Los nombramientos más conflictivos giraron en torno a la juventud. Amplios sectores del peronismo los consideraban como «recién llegados» a un movimiento que había debido enfrentar la represión y la proscripción política. El abogado Eduardo Zannoni fue designado ministro de Gobierno con 31 años de edad; su trayectoria política estaba ligada a la juventud, aunque había sido asesor de varios gremios $^{17}$. También Florentino Cortez logró el cargo de ministro de Bienestar Social y su base de apoyo lo encontraba en la Juventud Peronista, la Coordinadora y algunos gremios como ATSA. Finalmente Francisco Reig, de 30 años de edad, quien había sido propuesto por los gremios relacionados con el magisterio, por los maestros más combatientes y algunos integrantes de la Casa del Maestro. Uno "de los funcionarios que era bastante nuestro era el Gordo Reig, el Peque Gil, subsecretario de Cultura y Carricondo estaba también ahí, era de San Martín, toda gente pro-monto y pro-M artínez Baca"18. De esta manera, tanto la pertenencia sectorial como el lugar de origen muestran el peso relativo que poseían en la configuración de la administración pública.

La designación de las segundas líneas también generó conflictos. U na de las designaciones más controvertidas fue la de Juan Carlos Cerutti en la subsecretaría de gobierno. M ientras que los sectores gremiales se encontraban perplejos frente a la composición de los cuadros políticos, administrativos y burocráticos, la "Tendencia Revolucionaria" observaba que Martínez Baca no ofrecía indicios certeros del cambio radical que esperaban. Paulatinamente, el gobierno fue presionado por las fuerzas centrífugas que integraban el partido.

Los enfrentamientos comenzaron el primer día de asunción del gobierno peronista. El 25 de mayo de 1973, miembros de la Coordinadora se enfrentaron con obreros de la U O M. D urante el discurso del gobernador en la Legislatura, grupos vinculados con la "Tendencia" arriaron la bandera argentina y junto con ella izaron una que llevaba inscriptas las insignias de las Fuerzas Armadas Revolucionarias (FAR) y Montoneros ${ }^{19}$. Este suceso exacerbó el ánimo de gremialistas que se encontraban en las inmediaciones de la Legislatura.

Las presiones sobre el gobernador fueron en ascenso tras la renuncia del presidente Cámpora el 13 de julio de 1973 y el ascenso de

17 Claves para interpretar los hechos, 8/6/73:5. Los Andes, 25/5/73:11.

18 Entrevista a Guillermo Martínez Agüero, di rigente montonero, real izada en 2003 (De Marinis y Ábalo 2005:86).

19 Los Andes, 26/5/73:11. Cfr. (De Marinis y Ábalo 2005:134). 
Lastiri como presidente provisional. En efecto, tanto el vicegobernador Carlos Mendoza, el presidente del senado Edgardo Boris y el presidente de la Cámara de Diputados, Gabriel Montoro solicitaron a Martínez Baca la renuncia de los ministros más comprometidos ideológicamente, ajenos, a su juicio, a la tradición del justicialismo ${ }^{20}$. Los rumores de una posible intervención trascendían a través de los medios periodísticos; esta medida se había convertido en un escenario posible frente a la coyuntura provincial. A pesar de la búsqueda de la gestión de editar una imagen sólida, al gunos sectores gremiales, especialmente los relacionados con Fiorentini buscaron agitar ese fantasma frente a la «nfiltración» de sectores extraños a la doctrina justicialista.

\subsection{La consolidación del arco opositor: la violencia gana las calles}

Frente a la división interna del peronismo, Martínez Baca persiguió imprimir una imagen de tranquilidad y unidad, depositando en la figura de Perón la capacidad para aglutinar las fuerzas divergentes. Las elecciones presidenciales de septiembre de 1973 constituían un escenario propicio para esta estrategia. No obstante, Perón se había mostrado indiferente frente al conflicto provincial, dejando que se dirimiera por sus propios carriles políticos. Martínez Baca confiaba que "estando Perón al frente de la conducción nacional va a unificar todas las tendencias que hay dentro del justicialismo. Es un hecho evidente. U nificando el peronismo que es la mayoría del país, los demás argentinos que tienen la esperanza de que su país se realice va a apoyar una cosa organizada, clara, decidida con un rumbo marcado" (De Marinis y Ábalo 2005:180).

Las disputas buscaron matizarse en la campaña electoral con el fin de obtener resultados abultados. Desde la gobernación había que reconstruir la imagen de "unidad del movimiento". No obstante, el 19 de septiembre estalló el conflicto educativo, una de las carteras más cuestionadas por la filiación ideológica del ministro Reig. A pesar de la gestión relativamente exitosa que había logrado ${ }^{21}$, especialmente en

20 Claves para interpretar los hechos, 20/7/73:41.

21 En un artículo aparecido en la revista Claves para interpretar los hechos de julio de 1973, se rescata la figura del ministro Reig por la función ejercida en torno al problema docente "Al ministro Francisco Reig, de Cultura y Educación le debe el gobierno de Mart́́nez Baca uno de sus más espectaculares triunfos en el corto lapso transcurrido: la solución del problema 
referencia a la mejora salarial, las presiones sobre su figura no disminuyeron. La crisis se desató en el momento en que fueron inaugurados los seminarios educativos cuyo objetivo era establecer pautas para la elaboración de la Ley General de Educación. En ellos participaban los docentes como miembros activos en la confección de propuestas y proyectos para mejorar el aspecto curricular. N o obstante, el "Consejo Provincial de Educación Católica" hizo explícito el pedido de participación de los docentes privados. En esta oportunidad, el gobierno a través del Subsecretario de educación, Julio Carricondo, aprobó el pedido con la aclaración de que los privados debían acatar las disposiciones emanadas de lo que resolvieran los seminarios (Álvarez 1997:69; De Marinis y Ábalo, 2005:240). Asimismo este sector, hegemonizado por las instituciones confesionales, elevó sus críticas por el tono ideológico que propiciaban las pautas educativas establecidas por el gobierno. Según Álvarez, las propuestas de inspiración revolucionaria fueron denunciadas por la Liga de Madres de Familia, quienes encontraban en el documento sobre los "Lineamientos Generales sobre Educación Popular" concepciones imbuidas del ideario marxista.

Los laicos, en especial los padres de alumnos de colegios privados, apoyados por el O bispado, organizaron la "Marcha del Silencio"22, para hacer visible la «nfiltración marxista» en el área educativa. La Iglesia siempre había apetecido propiciar las reformas atendiendo a los valores católicos para llevar adelante el "programa de restauración espiritual de la Nación" (Caimari 2002:446), asediado por los valores laicos que habían primado en la educación argentina con la promulgación de la ley 1420. Los católicos veían que la reforma fomentaba la destrucción de la familia y exacerbaba el conflicto social a través de consignas revolucionarias. El clima de confrontación y revuelta en torno al problema educativo favoreció a los partidos opositores, que pronto ofrecieron sus apoyos explícitos a los manifestantes en los últimos tramos de la campaña electoral. Sin embargo, la identidad católica no logró nuclearse en una clara identidad política. En este sentido, el análisis del constitucionalista mendocino Dardo Pérez Guilhou asevera esta hipótesis: "Ese tema de laica o libre provoca manifestaciones como hay algunas, contra la Ley de educación que quiso dictar el gobernador peronista primero con Cámpora, que era Martínez Baca.

docente", esto se debeala mejora salarial que recibió el sector del magisterio. Cfr: Claves para interpretar los hechos, 6/7/73:21.

22 Los Andes, 20/9/73:6. 
(...) Provocan movilizaciones pero solucionado el problema, desaparece. Eso que vos decís 'los cristianos, qué importante que han hecho esta manifestación a favor de la enseñanza libre' al otro día votan todos por los radicales o votan todos por los socialistas o votan todos por los demócratas"23. En suma, el catolicismo no ejerció una oposición directa al peronismo.

Si bien las hostilidades entre católicos y el gobierno lograron dirimirse parcialmente, el peronismo obtuvo una abultada victoria en M endoza para la elección presidencial de septiembre. Los resultados electorales mostraron un apoyo masivo a la candidatura de Perón, logrando el $64,75 \%$ de los votos ${ }^{24}$. El análisis de esta elección sugiere, por un lado, que el electorado mendocino ofrecía pautas claras de apoyo al gobierno. Si bien en esa oportunidad se elegía solo presidente y vice, los resultados respaldaban tanto a Perón como así también a la gestión que llevaban adelante sus cuadros desde el 11 de marzo.

Los resultados electorales no lograron apaciguar las tendencias entre los integrantes del movimiento. El asesinato del sindicalista Rucci a días de las elecciones exacerbó el clima enrarecido y promovió que se tomaran medidas contra la «subversión». N o obstante, siguieron en escalada ascendente los modos violentos de expresión de los intereses políticos. En octubre estalló una bomba en el domicilio del profesor Enrique D ussel, filósofo de la liberación, y otra bomba en el despacho de Martínez Baca. Asimismo, fueron agredidos los dirigentes comunistas Benito M arianetti, Angel Bustelo y Jacinto de la Vega. Según la prensa, los atentados se atribuyeron al Comando de Fuerzas Anticomunistas José Rucci25.

En concatenación con el ascenso de la violencia, los apoyos políticos del gobernador se fueron diluyendo con celeridad desde octubre. La "ortodoxia" vio fortalecida su posición con la llegada del Perón al poder. El Congreso peronista de Mendoza, cuya representación mayoritaria estaba en manos de los sindicalistas, pidió a la Legislatura el retiro del apoyo al Gobernador. Este comunicado suscitó la división del bloque peronista, perdiendo la mayoría absoluta en la Cámara

23 Entrevista realizada por ClaudiaTouris, Mendoza, diciembre 2002.

24 En este porcentaje se ha considerado los votos del FREJULI más los obtenidos por el FIP (Frente de Izquierda Popular), faltando escrutar 4 mesas. Los Andes, 24/9/73:1.

25 Los Andes, 23/10/73:1, 6, 7. De Marinis y Ábalo (2005:260). 
Baja. Doce diputados ${ }^{26}$ de un total de 28 rechazaron el comunicado del Congreso peronista, conformando el "Movimiento peronista de la Verticalidad" que apoyaba a Martínez Baca.

Las pujas internas se cristalizaron a partir de los cambios realizados en los ministerios. El conflicto se dirimió en la Nación desde donde "se le planteó a Martínez Baca la exigencia: todo su gabinete debía renunciar para nombrar uno nuevo"27. Por ello se reemplazó a Zannoni, uno de los ministros más cuestionados, por Pedro Baglini, un penalista que había integrado el ministerio de Gobierno durante la administración de Evans ${ }^{28}$. También se alejó de su puesto al ministro de educación Reig y al de economía Sebastián Baztán, quienes fueron reemplazados por Bernal y Caplán. El ministerio de O bras y Servicios Públicos quedó en manos de Paulino Huerta, dirigente que no había sido atacado por su trayectoria política. A principios de noviembre faltaba la designación del ministro de Bienestar Social, nombre que debía surgir a partir de una terna propuesta por la CGT ${ }^{29}$. A través de los cambios sugeridos, el gobernador buscaba frenar a los sectores opositores que se multiplicaban con el desarrollo de su gestión.

El aislamiento de Martínez Baca era cada vez mayor entre las filas del justicialismo. Tanto el sindicalismo como Montoneros y la Juventud Peronista (JP) veían con resquemor la posibilidad de continuidad del primer mandatario provincial. El sindicalismo buscaba mayores posiciones de poder en el Estado provincial como en el partido. Montoneros y la Juventud Peronista, no apoyaron la gestión, acentuando su estrategia "militarista" ya que percibían indicios reformistas seguidos por el gobierno.

Martínez Baca avizoraba los efectos adversos de la puja intestina en los resultados de su gestión administrativa y el escaso margen de maniobra que poseía el Poder Ejecutivo. En un reportaje realizado por la revista política Claves para interpretar los hechos, el goberna-

26 Los diputados que apoyaron a Mart́nez Baca fueron: Molina, Montoro, Lilloy, Berdejo, Ghilardi, Emmi, Mart́n, Crimi, Andreoli, Pérez, Vilches y Davire Los 16 restantes “Diputados J usticialistas Ortodoxos" son Argüello, Bustamante, Cornejo, Díaz de Rivero, Donatti, Hinojosa, Leotta, Lucero, Mancilla de Tejada, Méndez, Mogni, Navas, Ortiz, Rodríguez, Videla y Yoma. Los Andes, 30/10/73:5. De Marinis y Ábalo (2005:265-266).

27 Claves para interpretar los hechos, 9/11/73:2.

28 Entrevista a Gerónimo Morgante realizada en 2003 (De Marinis y Ábalo 2005:129). Cfr. Claves para interpretar los hechos, 9/11/73:2.

29 Este puesto quedó cubierto a fines de noviembre con la designación de Arturo Ruiz Villanueva. 
dor expresó que "por la discordia interna del movimiento, no hemos podido actuar con la energía necesaria para realizar el cambio. Aquí para cambiar un empleado hay que consultar al concejal, al intendente, al diputado, al senador, al secretario general del movimiento, que nunca se han podido poner de acuerdo entre ellos"30. De esta manera, los mecanismos del Estado, cooptados por las corporaciones, aceleraban el proceso de crisis que vivenciaba el poder político provincial.

\section{Los embates de la lucha intestina: el problema de Giol y las causales del juicio político}

\subsection{Los dilemas administrativos de Giol}

La crisis en el seno del gobierno trajo aparejada una virtual parálisis de la administración pública y de la economía. El proceso de toma de decisiones se vio entorpecido por la divergencia de miradas y colapsado por las demandas contrapuestas de actores que buscaban obtener beneficios de las estructuras estatales. La inmovilidad en la gestión estatal se exhibía también en el manejo de Giol, empresa estatal donde la oposición al gobierno encontró indicios para la realización del juicio político. A partir de los manejos comerciales y financieros de la empresa estatal, el poder legislativo encontró la vía para responsabilizar al ejecutivo de su escasa habilidad para la administración de los asuntos públicos.

La situación que presentaba Giol durante la administración de Martínez Baca no difería de las problemáticas que había atravesado el gobierno desde el 25 de mayo (OIguin 2008). El primer directorio había renunciado, producto visiones encontradas en el partido. Frente a esta coyuntura, al gobernador le resultó dificultoso el nombramiento de uno nuevo. Por ello, Martinez Baca y Caplán decidieron la intervención de Giol, nombrando a Ramón José Roldán en ese cargo. La dirección de Roldán no logró resolver los problemas mayores de la empresa, y frente a conflictos desatados por la política de compras presentó su renuncia, quedando acéfala por 21 días durante el período vendimial. Según la revista Claves, "las diferencias de opinión acerca de a quién se debía nombrar, las presiones mutuamente neu-

30 Claves para interpretar los hechos, 13/4/74:10. 
tralizadoras de los diferentes grupos colaboraron para la creación de la «impasse»" ${ }^{1}$. La situación de acefalía se agravaba por el momento del ciclo económico en que se produjo la dimisión ya que en el periodo de cosecha se requieren tomar decisiones estratégicas que impactan sobre el conjunto de la cadena productiva.

La situación de irregularidad en el manejo económico, financiero y administrativo de Giol despertó interés en la oposición, dentro y fuera del justicialismo. Para determinar el grado de responsabilidad de las autoridades y los posibles perjuicios para la economía regional, se constituyó una comisión senatorial en enero de 1974 para que investigara la política del gobierno en materia vitivinícola, especialmente el desempeño de Giol ${ }^{32}$. Por ello, la comisión indagó el accionar del interventor Roldán, el papel de los comisionistas en las transacciones realizadas y la política de compras de la empresa, en especial "una operación de compras de vinos realizada por la empresa estatal a la firma García y Rodríguez S.A.C.I.A." ${ }^{33}$. A través de cuatro informes realizados por la Comisión especial, se advirtió sobre un negociado que implicaba directamente al hijo Alberto Martínez Baca, en el cual había tomado conocimiento el gobernador ya que la suma de dinero derivada de la transacción había sido depositada en la cuenta del Banco Hispano Ítalo Libanés que el primer mandatario provincial poseía en la ciudad de San Rafael (De Marinis y Ábalo 2005:348).

Los informes senatoriales dieron lugar al pedido de juicio político. El cuerpo de senadores elaboró y aprobó una resolución para que la Cámara de Diputados analizara la aplicabilidad del artículo constitucional. Para consustanciar el inicio del juicio se necesitaba la aprobación de dos tercios de la Cámara de Diputados. Por ello, la decisión que adoptaran los bloques partidarios era fundamental para llevar adelante el trámite administrativo. La composición partidaria de la Cámara Baja arrojaba una imagen parcelada: el bloque peronista contaba con 28 diputados, el demócrata con 11 y el radical con 9. Por lo tanto, se requerían 32 votos afirmativos para el inicio del juicio político al gobernador. La división del bloque justicialista consumó la alternativa de establecer mecanismos para desalojar a Martínez Baca del gobierno.

31 Claves para interpretar los hechos, 8/3/74:13.

32 Las denuncias sobre negociados partieron del diputado demócrata Larraburú, cuando la comisión ya estaba funcionando. Cfr. Claves para interpretar los hechos, 29/3/74:7.

33 Los Andes, 19/3/74. 
Por ello, se elevaron a la Cámara de Diputados cuatro pedidos de juicio político que se enmarcaron en la figura de "mal desempeño en el ejercicio de las funciones" 34 . En ese marco, el partido justicialista no sólo aceleró la investigación efectuada por la comisión, sino que presentó un pedido específico a través de Made y Teruel. De esta manera, el juicio político cristalizaba las divisiones internas, las cuales en esa coyuntura política reflejaban una imagen irreconciliable. Q uienes apoyaban la acusación tenían como referentes máximos a la "ortodoxia" sindicalista, la cual propiciaba que el ejecutivo recayera en manos de Mendoza. En oposición se encontraban los resabios de la tendencia revolucionaria.

U no de los aspectos de mayor relevancia del juicio se relacionaba con la oposición parlamentaria: el partido demócrata y el radical. Hasta ese momento, los conflictos del gobierno se dirimieron al interior peronismo. Esta nueva situación colocó tanto a radicales como a demócratas en un papel activo respecto al diagnóstico y evolución del gobierno. La postura de los legisladores en esta coyuntura era decisiva para la continuidad de la vida institucional de la provincia. El parlamento se convirtió en caja de resonancia de los embates en torno al poder y la administración provincial.

En la Cámara Baja se logró obtener la mayoría necesaria para el inicio del procedimiento jurídico. La decisión mayoritaria contó con la oposición de diez diputados ${ }^{35}$. Siguiendo lo establecido por el artículo 109, la Cámara de Diputados nombró por votación directa una comisión encargada de investigar lo acaecido y quedó integrada por Lilloy, Fadrusco, Falaschi, Farías, G hilardi, M olina y Fernández. Un examen de la correlación de fuerzas dentro de la comisión permite bosquejar la tendencia valorativa del informe entregado para la aprobación 0 rechazo y sus consecuentes implicancias para el destino del gobernador. En el caso del justicialista Eduardo M olina, si bien su postura exhibía cierta reserva con respecto a la gestión martinezbaquista, en esta oportunidad defendió el desempeño del ejecutivo por no encontrar causales reales para el ejercicio de juicio político. "Molina es un convencido de que el juicio político no es más que una maniobra contra

34 Constitución de la Provincia de Mendoza 1999:109.

35 Molina, Montoro, Ghilardi, Yoma, Crimi, Andreoli, Mart́n, Davire, Emmi y Vilchez Vega. Los Andes, 3/4/74. 
Martínez Baca y, salvo demostración en contrario, se demuestra que votará a favor del gobernador" 36 .

Por el contrario, dentro de la comisión de Diputados hubo miembros que encontraron favorable la realización del juicio. El más ferviente defensor de esta postura fue el demócrata Ariosto Falaschi, con una fuerte tendencia antiperonista y perteneciente al bloque que exigía la renuncia del gobernador. Fernández, perteneciente al partido demócrata consensuaba esta postura, aunque mostraba sus reservas respecto de hacerlas públicas. No obstante, las mayores expectativas estaban depositadas en los miembros restantes, quienes pertenecían al partido justicialista y que no habían formulado declaraciones a favor de la gestión de Martínez Baca.

Un aspecto que ofrece aristas relevantes es la imagen que fue creando y recreando la prensa en torno a la problemática políticainstitucional por la que atravesaba la provincia. Los argumentos que ofrecía Martínez Baca intentaban hacer explícito el "contubernio" en el partido gobernante y cómo el problema de la administración de Giol servía de instrumento para orquestar la oposición. En una entrevista realizada por la revista Claves, M artínez Baca expresaba que "en este episodio del juicio no hay más que un trasfondo político. Es la culminación de un proceso iniciado el 11 de marzo y que llega hasta hoy. La escalada de quienes intentan quebrar el principio de autoridad es un hecho concreto que, así en otras partes, también se da en Mendoza. En este lapso, a mis enemigos les fueron fracasando una por una las tácticas que usaron para quitarme del camino: primero fue la acusación -jamás probada- de un gabinete comunista; luego cambiaron de sambenito: la Tendencia Revolucionaria; ni la enfermedad de mi vista perdonaron y, caso inédito, cuando presionaron para cambiar totalmente mi elenco de colaboradores, exigieron el acuerdo previo del vicegobernador. Y así desembocamos en el caso desgraciado de Giol. Si hay algo mal hecho, el culpable no es no es ni el gobierno ni el ministerio específico: los directos responsables son los directivos de la empresa" ${ }^{37}$.

36 Claves para interpretar los hechos, 4/5/74:2.

37 Entrevista realizada por la revista Claves para interpretar los hechos a Martínez Baca (De Marinis y Ábalo 2005:361). 


\subsection{La "solución" presentada al conflicto peronista: la suspensión de Martínez Baca y la intervención federal de la provincia}

Para comprender los mecanismos del juicio es necesario confrontar las estrategias discursivas de la defensa y la acusación. La defensa del gobernador, llevada adelante por Alfredo Gómez Chavero y Raúl Ábalos, basó principalmente su alegato en las fallas en el proceso administrativo de la comisión investigadora del Senado como de la Cámara de $D$ iputados. M encionadas fallas se avizoraban en la falta de una reglamentación específica que requeriría el juicio político. Gómez Chavero y Ábalos sostenían la postura de que los pedidos de juicio político habían partido de informes elaborados por la comisión especial de la cámara de senadores y la ley esbozaba claramente que "el senado no podrá formar comisiones especiales para investigar la conducta de los funcionarios"38. Es decir, el Senado no podía ejercer un rol de fiscal, para luego erigirse en juez al constituirse en cámara de justicia.

Los argumentos que sirvieron para crear evidencia de la culpabilidad del gobernador focalizaban su atención en el aspecto jurídico. La acusación ${ }^{39}$ imputaba a M artínez Baca en primer lugar la "desviación de poder" por la intervención de Giol. En segundo lugar, se lo imputaba por "mal desempeño" en cuanto a la "violación del orden legal" de la Ley 3909 de Procedimiento administrativo, por dejar sin Directorio a la empresa vitivinícola. En tercer lugar, en referencia al amparo y auspicio por parte del gobernador de ciertas compras de la empresa estatal, la acusación rescataba la negociación entablada con la empresa "El Trébol", la cual fue realizada por medio de los comisionistas José Ramón Martínez y Juan Alberto Martínez Baca, hijo del gobernador.

La imputación penal se fundamentó en la violación del artículo no 248 del Código Penal por "abuso de autoridad" y en el artículo no 249 por "omisión de deberes". N o obstante, la descripción densa recayó en los delitos sobre presuntas "negociaciones incompatibles con la función pública", en donde se exaltaba el beneficio que había logrado Martínez Baca a través de las transacciones de la empresa estatal. Los documentos acreditados en la cuenta del Banco Hispano Italo Libanés servían de evidencia para corroborar esta imputación. Por ello se

38 Claves para interpretar los hechos, 4/5/74:3.

39 Dictamen por la mayoría, Diario deSesiones, H. Cámara de Diputados, 29/5 y 5/6-6/6/74:388 y ss. 
Io acusaba haber ejercido "delito en el ejercicio de sus funciones, al intervenir en las ventas de vinos que terceros, por intermedio de su hijo Juan Alberto Martínez Baca realizaron a Bodegas y Viñedos Giol E.E., llegando ese interés al extremo de recibir parte del beneficio pecuniario de la intermediación".

¿Cuál fue la estrategia seguida por los miembros de la comisión que votaron en disidencia total? En primer lugar, Molina, Fadrusco y G hilardi argumentaron en su escrito en disidencia ${ }^{40}$ en torno a la figura que se desprende de la Constitución Nacional. En el artículo no 45, se expresa que la Cámara de Diputados debe ejercer su función como acusadora y la Cámara de Senadores como Tribunal. Desde esta perspectiva, estas figuras habían sido violadas por el procedimiento administrativo ya que los pedidos de juicio partieron desde el Senado a partir de los informes de la Comisión especial. La disidencia trajo a colación experiencias similares en donde se había juzgado a las autoridades, destacando especialmente el móvil político que las estimulaba. A través de la jurisprudencia se arguyó sobre la parcialidad del Senado ya que "él juzgará según sus simpatías políticas y si se trata de un enemigo político hará lo posible para ampliar el alcance del crimen; si se trata de un amigo político, cerrará los ojos para no ver el crimen cometido".

El dictamen acusatorio aprobado por la mayoría de la comisión fue tratado por la Cámara de Diputados en la sesión del 5 de junio de 1974. El debate parlamentario exhibía posiciones enconadas. Allí los sectores opositores al gobierno buscaban obtener dos tercios de la Cámara para lograr la suspensión del gobernador. A partir de entonces, la Cámara de Senadores se erigiría en Cámara de Justicia para contestar la acusación dictaminada.

En la instancia de votación de la Cámara de Diputados, el bloque justicialista se encontraba dividido desde fines de octubre de 1973. El Partido Demócrata había decidido votar en bloque por la acusación llevando una estrategia coherente en el conjunto del juicio político. El bloque que definía la votación era el radical, quien dejó en libertad de acción a sus diputados. El dictamen acusatorio recibió el voto afirmativo de 18 diputados justicialistas, 11 de los demócratas y 3 de los radicales. Estos últimos votaron por la acusación, pero sólo en referencia al mal desempeño en las funciones, sin creer en las imputaciones penales descritas en el dictamen. A partir de esta decisión de

40 Informeen disidencia, Diario de Sesiones, H. Cámara de Diputados, 29/5 y 5/6-6/6/74:440 y ss. 
la Cámara, M artínez Baca fue alejado de las funciones inherentes al Poder Ejecutivo.

El escaso margen con que se logró obtener los dos tercios ofrecía un claro panorama de las tensiones que exhibía el proceso de juicio político. La opinión pública avizoraba perpleja lo ocurrido en el seno del gobierno democrático. "Cuando pierde el juicio no hay ninguna reacción popular. No hubo absolutamente nada" ${ }^{41}$. Si bien, las filas que defendieron al gobernador no reclutaron fuerzas para manifestarse públicamente, tampoco hicieron lo propio las líneas que promulgaban el juicio. En esa coyuntura se hizo cargo de la gobernación Carlos Mendoza, quien para intentar apaciguar el clima de disputa decidió no propiciar cambios en las filas ministeriales. No obstante, la mayoría de los ministros renunciaron, permaneciendo en el gobierno sólo Pedro Baglini y González Bonorino ${ }^{42}$.

A partir del alejamiento Martínez Baca el 6 de junio de 1974, el Senado se erigió como Cámara de Justicia para finalizar el proceso de juicio político. En esa instancia, el gobernador suspendido tenía una nueva oportunidad para presentar evidencias en su defensa. No obstante, ante los conflictos irresueltos en torno a las divisiones internas, fue tomando fuerza la propuesta de intervención federal a los tres poderes de la provincia. Esta propuesta, gestada en los intersticios del Ministerio del Interior, buscaba fomentar la unión del peronismo resquebrajado hasta sus últimas instancias en el proceso de juicio político. Delegaciones de dirigentes sindicales intentaron frenar estos proyectos ya que verían recortada su cuota de poder. De acuerdo al escenario diseñado por la revista Claves para interpretar los hechos, de postura martinezbaquista, las alternativas que se tejían a nivel nacional contemplaban sólo dos posibles caminos: la intervención federal o el acuerdo senatorial, ya que se había violado en aspectos jurídicos la constitución provincial. "Si M artínez Baca resulta absuelto, los enfrentamientos con el ejecutivo recrudecerían y la división partidaria se ahondaría. Igualmente, si M artínez Baca es destituido, un ponderable sector del peronismo quedaría resentido cerrando todas las puertas a la unidad partidaria. En consecuencia se impone la intervención federal 0 un acuerdo generoso entre el mandatario y los senadores de su

41 Entrevista a Gerónimo Morgante realizada en 2003 (De Marinis y Ábalo 2005:271).

42 Claves para interpretar los hechos, 28/6/74:6. 
partido"43. Este último escenario no tenía indicios de materializarse, ya que la postura de esta cámara resultó clara al momento de apoyar el accionar de la comisión senatorial, las cual dio lugar al pedido de juicio político.

Las negociaciones entabladas con el ministro Llambí partieron tanto de la gestión de Martínez Baca como del sector gremial. Por un lado, el gobernador suspendido buscaba la intervención para impedir el copamiento del partido por el sindicalismo. Por el contrario, el sector liderado por Mendoza buscaba la finalización del juicio por medios institucionales. El diseño priorizado por el ministerio acentuaba la intervención federal, la cual tomó forma a través del proyecto de ley enviado a las cámaras en julio de $1974^{44}$. Esta ley recibió el apoyo de la cámara de diputados y senadores de la Nación ${ }^{45}$ y en consecuencia, se dejó sin finalizar el juicio político. La solución planteada a nivel nacional buscaba matizar las aristas de conflicto, arrojando un manto de silencio sobre el procedimiento jurídico. Tanto las denuncias de inconstitucionalidad como las indagaciones sobre los funcionarios de segundas y terceras líneas quedaban soterradas ante la decisión adoptada a nivel nacional. Para la el gobierno nacional, era necesario reestablecer los canales de autoridad, debilitados hasta el extremo mediante la crisis política.

La intervención buscaba rescatar los fragmentos de institucionalización y la normalización en el peronismo. No obstante, la dinámica gubernamental exhibía heridas profundas, difíciles de subsanar. Muerto Perón, las beligerancias internas se ahondaron, los actores políticos aumentaron sus demandas ante un Estado con disminuidas capacidades. El débil aparato estatal, invadido por la lucha corporativa y conducido por una figura que ya no poseía un capital político sustentable, trajo aparejado la parálisis de la economía y la administración pública. El gobierno democrático se diluía ante el robustecimiento de una oposición que exigía soluciones concretas. El clima de violencia y la lucha entre sectores terminó enrareciendo la vida política ya que el gobierno mostraba signos de agotamiento.

43 Claves para interpretar los hechos, 28/6/74:5.

44 Los Andes, 13/7/74: 1.

45 Los Andes, 26/7/74: 1. 
María Virginia Mellado

\section{Conclusiones}

El ejercicio propuesto ha permitido trazar algunas líneas de análisis acerca de la problemática que atravesó el peronismo en Mendoza y el desgaste sufrido en sus filas una vez ganadas las elecciones en marzo de 1973. Esta situación discordante establecida por las divisiones internas amenazaba tanto la estabilidad del gobierno como la supervivencia de las posiciones adquiridas en las estructuras de poder provincial.

Si bien la situación de estabilidad parecía haberse logrado con la asunción de Martínez Baca a la gobernación a través de acuerdos para confeccionar las listas de candidatos, los escasos y efímeros apoyos con los que contaba, especialmente entre los heterogéneos y fragmentarios sectores juveniles, no alcanzaron para consolidarse en la estructura partidaria. Tanto el partido como el sector gremial buscaron reeditar prácticas que permitieran ir acrecentando espacios de poder, con la consecuente pérdida de capital político de la fracción martinezbaquista. Paulatinamente, los sectores que habían prestado apoyo a Martínez Baca no lograron controlar la estructura del partido. La presión del aparato partidario y burocrático de los sectores sindicales debilitó las posiciones juveniles. Cuando la situación coyuntural ofrecía indicios de lograr una unidad, desplazando a un sector importante del peronismo, la intervención federal fue la solución planteada por el gobierno nacional como remedio ante las luchas intestinas, buscando reestablecer los canales de autoridad dentro del partido y del gobierno. No obstante, las legitimidades habían sufrido un impacto de envergadura.

Asimismo, el análisis de la disputa por los cargos en los ministerios permitió visualizar las divisiones internas. El personal político que integró el gobierno provino de diferentes experiencias previas. Si bien un gran número de dirigentes llegaba a la política a través de su militancia en las corporaciones, especialmente del sindicalismo, también fue importante la imbricación de las capas medias a través de la militancia universitaria evidenciada en la selección de los ministros jóvenes. Esta elección de dirigentes fue criticada por la "ortodoxia". Con la llegada de Perón a la presidencia, el clima enrarecido se acentuó y la oposición al gobierno logró consolidarse por medio de manifestaciones públicas, como la "M archa del Silencio", hechos de violencia en las calles y la pérdida de mayoría automática en la Cámara Baja. 
Atendiendo al proceso específico de juicio político desatado luego de que se tomara conocimiento público de la política de compras y las irregularidades en la administración de la empresa estatal Giol, este instrumento jurídico se erigió como modalidad para dirimir el conflicto al interior del peronismo. El parlamento se convirtió en caja de resonancia de los procesos políticos provinciales. El juicio político colocó a los partidos opositores en jueces de la disputa. Al encontrarse dividido el bloque peronista en la Cámara de Diputados, el rol del Partido Demócrata y el Radical fue relevante para apartar al gobernador de sus funciones.

El juicio político cristalizó las tensiones al interior del justicialismo. El partido, a través de dos dirigentes jóvenes, favoreció e impulsó el inicio del proceso jurídico. Cada uno de los grupos contendientes exhibió estrategias diferenciadas en torno de la acusación o de la defensa. En el caso de la acusación, se hizo hincapié en el mal desempeño de las funciones y en los delitos cometidos, especialmente en referencia a la figura de "negociaciones incompatibles con la función pública". A través de la presentación de los actos de corrupción por intermedio del hijo del gobernador, se construyeron pruebas que evidenciaban los manejos irregulares en la empresa estatal. En contraste, la estrategia de defensa trajo a colación las anomalías en las que había incurrido el proceso administrativo, especialmente porque el Senado había jugado un papel acusatorio. Asimismo el escrito de la defensa advertía sobre el trasfondo político soterrado por la investigación, los grupos disidentes habían incentivado la indagación de fenómenos que no le competían estrictamente a M artínez Baca.

El proceso jurídico se vio interrumpido por medio de la intervención federal. La decisión del gobierno nacional estaba fundamentada en la necesidad de reestablecer los canales de autoridad tanto del Partido Justicialista como del gobierno provincial. La corrosión de los mecanismos institucionales había llegado al extremo de disolver las jerarquías en la estructura de poder. Asimismo, la colonización de las corporaciones había generado una parálisis de la administración pública evidenciada en la falta de decisión del ejecutivo frente a problemas acuciantes de la gestión. Las presiones internas habían impedido la toma de decisiones eficientes.

En suma, el análisis del juicio político al gobernador Alberto Martínez Baca permitió reconstruir el itinerario del justicialismo provincial en la etapa democrática abierta en 1973. La división al interior 
María Virginia Melado

del gobierno exhibía la heterogeneidad de perspectivas y miradas que integraban el peronismo, como así también la diversidad de actores y sectores sociales adscriptos a su proyecto. Esta heterogeneidad evidenciada desde un punto de vista sociológico como ideológico es la que permite explicar tanto la errante gobernación de M artínez Baca como así también el inicio del juicio político y la decisión del gobierno nacional de intervenir la provincia de M endoza en julio de 1974.

\section{Referencias bibliográficas}

Altamirano, Carlos. "M ontoneros", en: Carlos Altamirano, Peronismo y cultura de izquierda. Buenos Aires: Temas Grupo editorial, 2001:121-140.

Álvarez, Yamile. "La educación en Mendoza durante el gobierno de M artínez Baca: los seminarios y el conflicto con padres y docentes". Revista de Estudios Regionales, CEIDER, 1997:65-80.

Brennan, James. El cordobazo. Las guerras obreras en Córdoba 19551976. Buenos Aires: Sudamericana, 1996.

Caimari, Lila. "El peronismo y la Iglesia católica", en: Nueva Historia Argentina, Tomo VIII. Buenos Aires: Sudamericana, 2002:441479.

Cueto, Adolfo et al. Historia de Mendoza. La etapa pendular 19551991. Primera parte (1955-1973) y segunda parte (1973-1991), Facs. 23 y 24. M endoza: Diario Los Andes, 1996.

De Marinis, Hugo y Ramón Ábalo. Mendoza Montonera. Memorias y sucesos durante el gobierno de Martínez Baca. Buenos Aires: Corregidor, 2005.

De Riz, Liliana. La política en suspenso 1966-1976. Buenos Aires: Paidós, 2000.

Gillespie, Richard. Soldados de Perón. Los M ontoneros. Buenos Aires: Grijalbo, 1987.

Gordillo, Mónica. "Los prolegómenos del Cordobazo: Ios sindicatos líderes de Córdoba dentro de la estructura de poder sindical". Desarrollo Económico, Vol. 31, n 122, julio-septiembre, 1991:163187. 
James, Daniel. Resistencia e Integración. El peronismo y la clase trabajadora argentina 1946-1976. Buenos Aires: Sudamericana, 1999.

Lanusse, Lucas. Montoneros. El mito de sus doce fundadores. Buenos Aires: Vergara, 2005.

Macor, Darío y Eduardo Iglesias. El peronismo antes del peronismo. Memoria e historia en los orígenes del peronismo santafesino. Santa Fe: U niversidad Nacional del Litoral, 1997.

y César Tcach (comp.) La invención del peronismo en el interior del país. Santa Fe: Editorial Universidad Nacional del Litoral, 2003.

Micale, Adriana. "Crisis y conflicto", en: Arturo Roig, Pablo Lacoste y M. Cristina Satlari, dir., M endoza a través de su historia. M endoza: Editora Andina Sur, 2004:367-405.

O Iguín, Patricia. "La intervención estatal en los mercados vitivinícolas. La función de regulación de las Bodegas y Viñedos Giol. M endoza, Argentina (1954-1974)". Revista Territorios del Vino, Año II, $\mathrm{n}^{\circ} 2$, 2008:67-107.

Pozzi, Pablo y Alejandro Schneider. Los setentistas. Buenos Aires: Eudeba, 2000.

Tcach, César. Sabattinismo y peronismo. Partidos políticos en Córdoba. Buenos Aires: Sudamericana, 1991.

Tortti, María Cristina. "Protesta social y 'Nueva Izquierda' en la Argentina del 'G ran Acuerdo Nacional'". Taller, Vol. 3, $n^{\circ}$ 6, abril 1998:11-39.

Waldmann, Peter. "Anomia social y violencia”, en: Alain Rouquié, comp., Argentina Hoy. Buenos Aires: Siglo XXI, 1982:206-248.

\section{Resumen}

Este trabajo examina la modalidad que exhibieron las divisiones internas del peronismo en la provincia de Mendoza, fenómeno que corroyó la experiencia gubernamental abierta en 1973. Ganadas las elecciones por el peronista Alberto Martínez Baca, se suscitaron una serie de conflictos internos en el justicialismo que perjudicaron la administración estatal de los asuntos públicos. La puja intestina entre 
los distintos sectores que conformaron el peronismo se dirimió por medio de la realización de un juicio político al gobernador, salida institucional que difirió de las alcanzadas en otros contextos provinciales. A través del análisis de las causales del juicio, de las estrategias llevadas adelante por la defensa y la acusación, el artículo busca restituir el itinerario del peronismo mendocino, divisando la heterogeneidad de perspectivas y miradas que lo integraban, como así también la diversidad de actores y sectores sociales que habían adscrito a su proyecto.

Palabras clave: peronismo, juicio político, Mendoza, élites políticas.

The outlines of the disintegration: the political judgment to the Governor Martínez Baca (Mendoza, 1973-1974)

\section{Summary}

This article goes through the modality of internal divisions that exhibited the peronism party from Mendoza throughout general elections in 1973. When the elections were won by the peronist Alberto Martínez Baca, a series of intern conflicts appeared in the winning party that damaged the state administration of public affaires. The internal struggle between the different sectors that makes up the peronism was solved with a political court judgment to the governor. This institutional solution differed from the ones taken in other provincial contexts. Through the analysis of the arguments of the court judgment and the strategies of the defense and the prosecution, the article searches to restore the itinerary of mendocinian peronism, focusing in its heterogeneity of perspectives and points of view, and also approaching the diversity of actors and social sectors that had endorsed to the peronism project.

Key words: peronism, political judgment, Mendoza, political élites.

Recibido: 30/06/08, aceptado: 13/04/09. 